\title{
Some new reactions and properties of xanthane hydride
}

\section{Victor V. Dotsenko1,2*, Tatyana Yu. Evmeshenko1, Vladimir D. Strelkov ${ }^{1,3}$, Fedor F. Chausov ${ }^{4}$}

${ }^{1}$ Kuban State University, 149 Stavropolskaya str, Krasnodar, 350040 Russia e-mail:victor_dotsenko@bigmir.net

${ }^{2}$ ChemEx Lab, Vladimir Dal' Lugansk National University, 20A/7 Molodezhny, Lugansk, 91034 Russia

${ }^{3}$ All-Russian Research Institute of Biological Plant Protection, Laboratory of plant growth regulators, 350039 Krasnodar, Russian Federation ${ }^{4}$ Udmurt State University, 1 Universitetskaya Str., 426034 Izhevsk, Russia

\begin{abstract}
Xanthane hydride (5-Amino-3H-1,2,4-dithiazole-3-thione) reacts with dicyandiamide to afford new 1,3,5-thiadiazine derivative. Xanthane hydride was found to be moderately active antidote towards herbicide 2,4-D, plant growth regulator and steel corrosion inhibitor.
\end{abstract}

Keywords: Xanthane hydride, 1,3,5-thiadiazines, corrosion inhibitors, herbicide antidots, plant growth regulators

Xanthane hydride (isoperthiocyanic acid, 5-amino-1,2,4-ditiazolin-3thione $\mathbf{1}$ ) is known as the very first organic compound obtained by Friedrich Wöhler, starting from inorganic compounds ( $\mathrm{HCl}$ and mercury thiocyanate) in 1821 [1,2], before the Wöhler's classical synthesis of urea from ammonium cyanate. The chemistry of xanthane hydride has been reviewed [1,3]. Due to the presence of nucleophilic thioxo- and amino groups, xanthane hydride could be considered as a reactive molecule useful as a starting point for construction of new heterocyclic compounds. We found that when a mixture of xanthane hydride 1 and dicyandiamide was refluxed in EtOH, a new 1,3,5- 
thiadiazine 2 was isolated, along with little amounts of sulphur. The mixture was separated by recrystallization. A proposed mechanism for the formation of 2 is shown in the Scheme below. The structure of 2,6-diamino-4-imino-4H1,3,5-thiadiazine 2 was confirmed by FTIR, NMR and LCMS data (Figures 1-3).

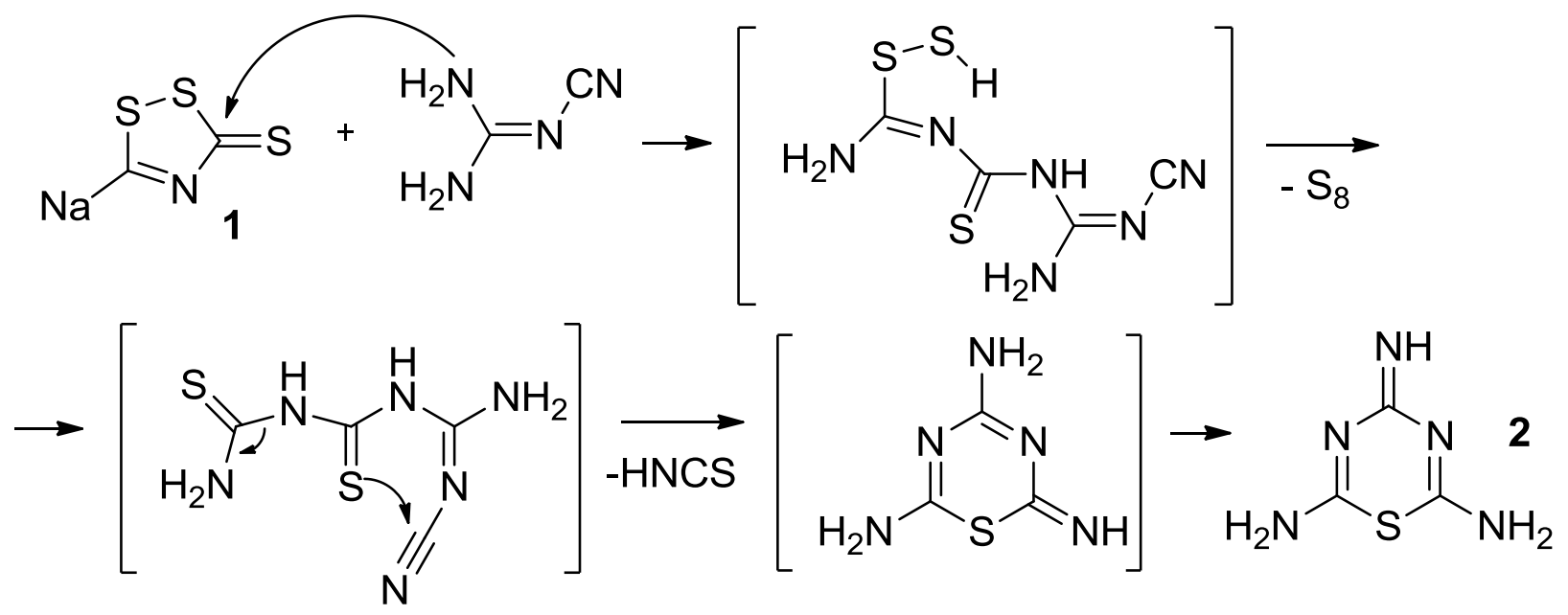

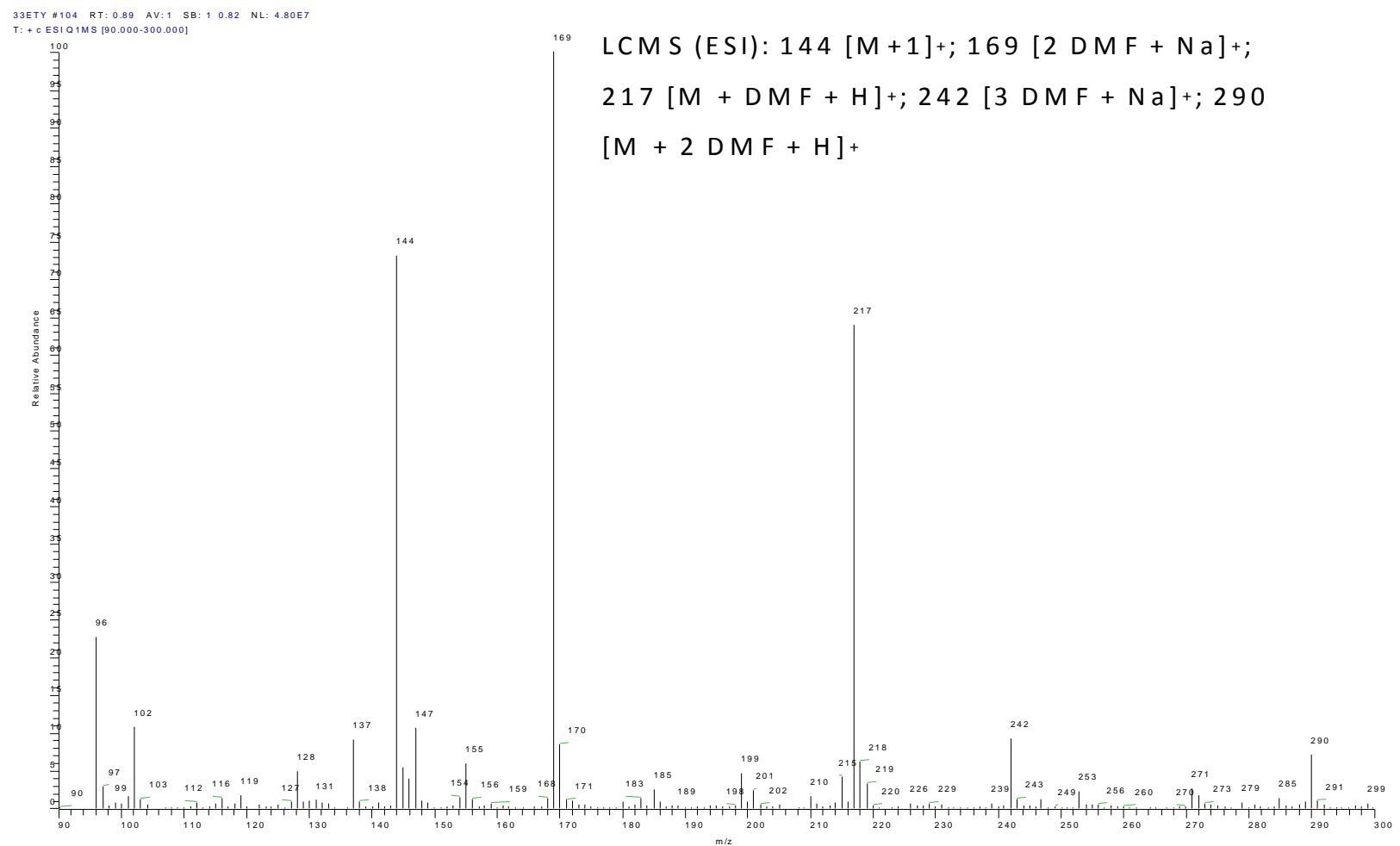

Fig.1. Mass-spectrum (ESI) of 2,6-diamino-4-imino-4H-1,3,5-thiadiazine 2.

The ${ }^{1} \mathrm{H}$ NMR spectrum of 2,6-diamino-4-imino-4H-1,3,5-thiadiazine 2 revealed the signals of two $\mathrm{NH}_{2}$ and one $\mathrm{NH}$ group, while ${ }^{13} \mathrm{C}$ NMR spectrum showed only two carbon signals confirming a symmetric structure of 2; noteworthy that any $\mathrm{C}=\mathrm{S}$ or $\mathrm{C} \equiv \mathrm{N}$ signals are absent. 


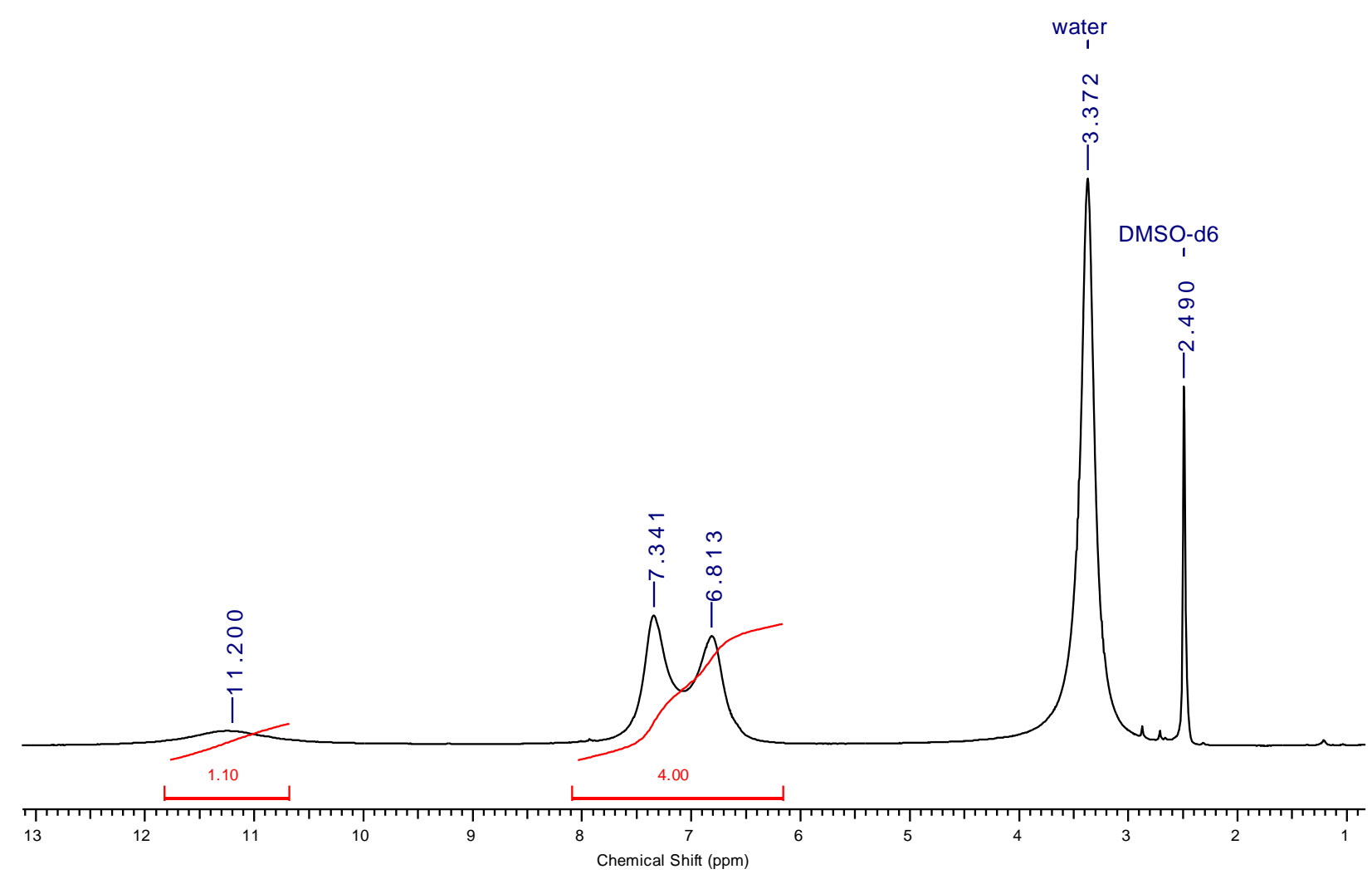

Fig. 2. ${ }^{1} \mathrm{H}$ NMR spectrum (400 MHz, DMSO-d $)$ of 2,6-diamino-4-imino-4H-1,3,5thiadiazine 2

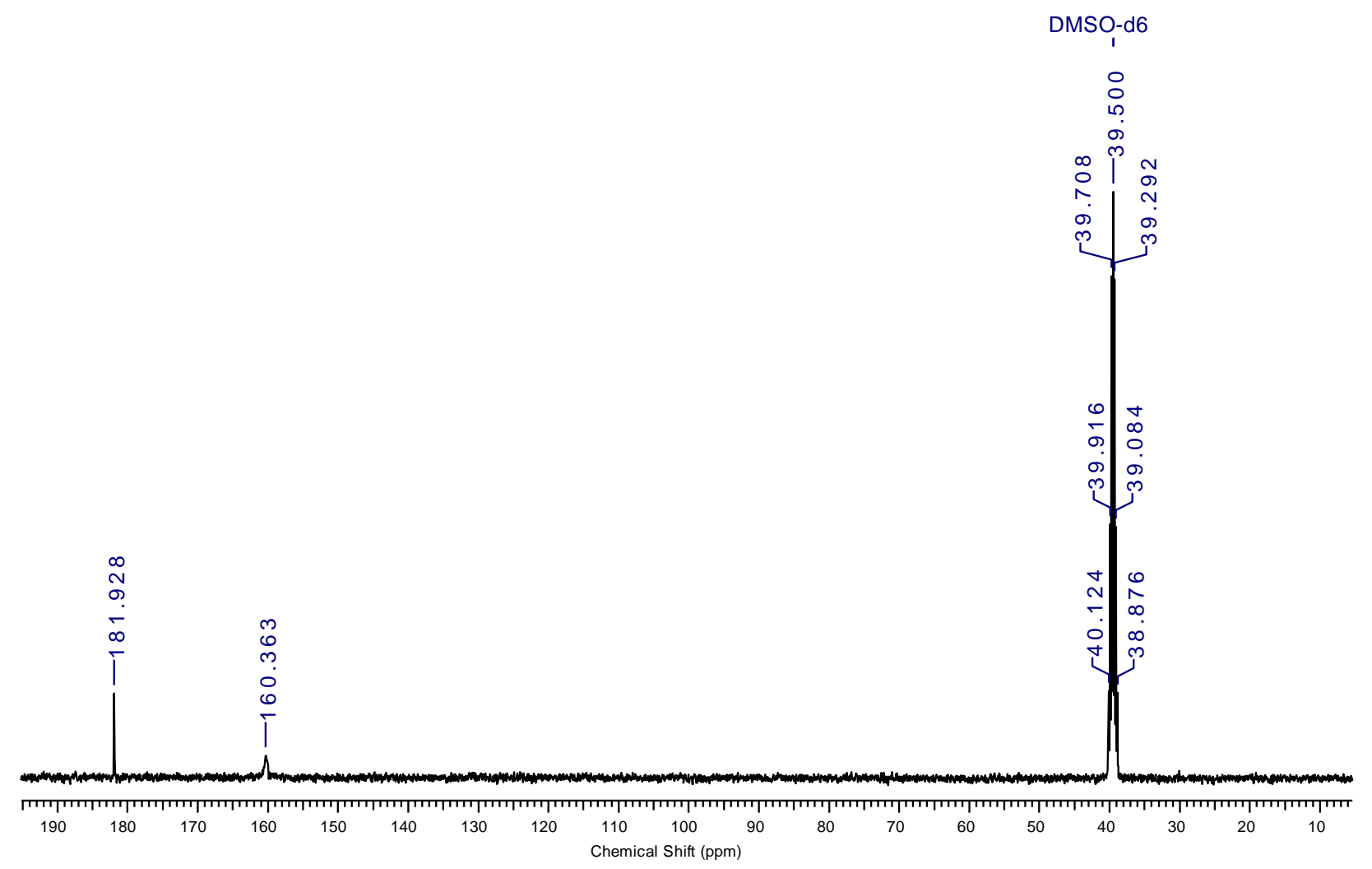

Fig. 3. ${ }^{13} \mathrm{C}$ NMR spectrum (101 MHz, DMSO-d $)$ of 2,6-diamino-4-imino-4H-1,3,5thiadiazine 2 
Some properties of xanthane hydride were studied. First, the effect of xanthane hydride on the corrosion kinetics of steel in a neutral aqueous medium was carried out on samples of steel 20 (GOST 1050) that were cutted from a single sheet of hot-rolled steel. A borate buffer solution $(0.2 \mathrm{~mol} / \mathrm{L}$ $\mathrm{NaOH}, \mathrm{H}_{3} \mathrm{BO}_{3}$ to $\mathrm{pH}=7.4$ ) was used. The studies were carried out on an automated potentiostat IPC-Pro-L by the potentiodynamic method in a threeelectrode electrochemical cell. was used. The Pt electrode was used as an polarizing electrode, $\mathrm{Ag}|\mathrm{AgCl}| \mathrm{KCl}_{\text {saturated }}$ electrode was used as the reference electrode, which was switched on through an electrochemical key to prevent contamination of the electrolyte with chloride ions. Before starting the measurements, the working electrode (sample) was kept at a potential of -900 ...-1000 mV (hereinafter all potentials are given in the reference electrode scale) for $15 \mathrm{~min}$. to remove a layer of oxidation products from steel surface.

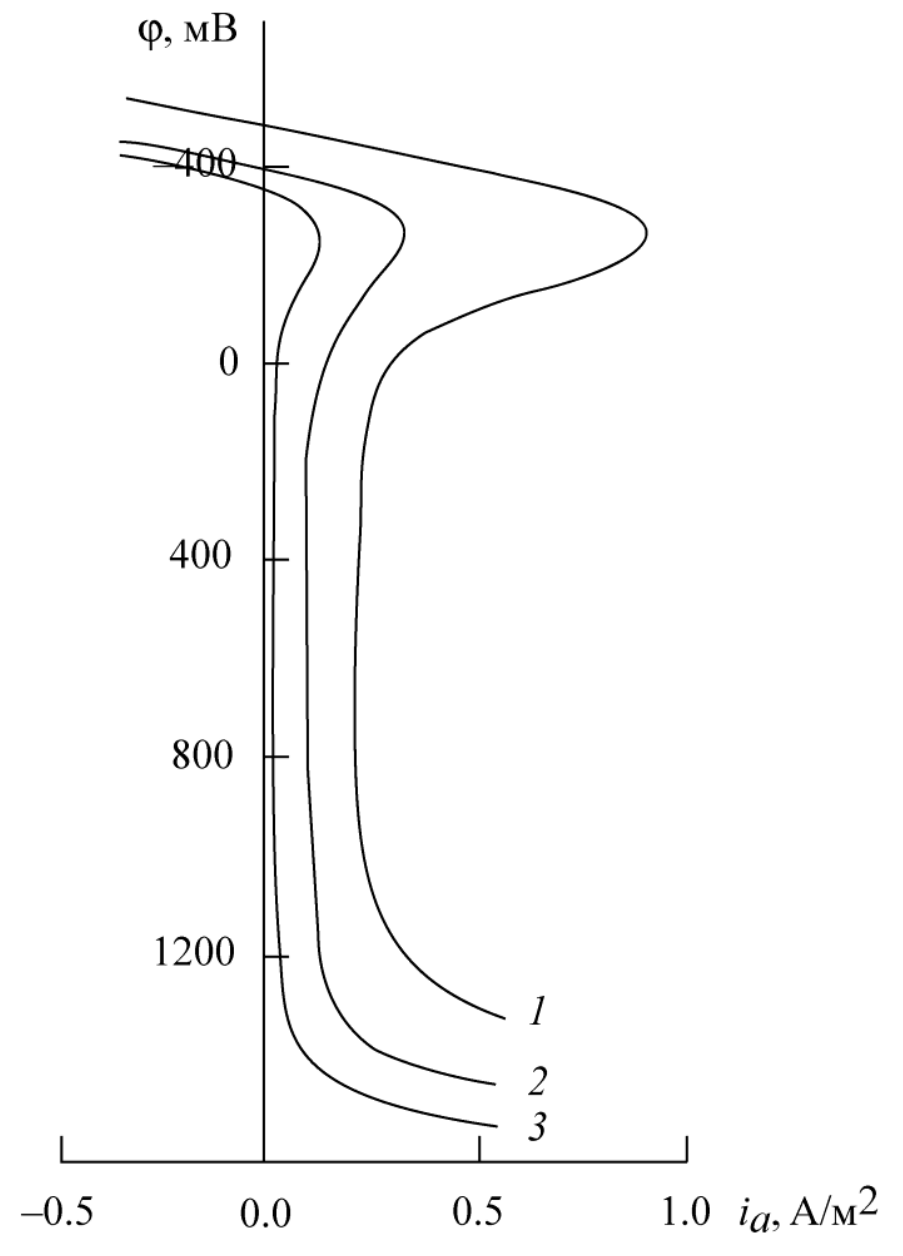

Fig. 4. Anodic polarization curves of steel samples 20 in borate buffer solution $p H=7.4$ with natural aeration: 1 - without inhibitor (blank), 2 and 3 - with addition of 0.5 and $1 \mathrm{~g} / \mathrm{L}$ of xanthane hydride, respectively, in the form of potassium salt.

Anodic branch of the polarization curve was studied in the potential range from -800 to $+1600 \mathrm{mV}$ at scan rate of 2 $\mathrm{mV} / \mathrm{sec}$. In the solution (without xanthane hydride), the anodic polarization curve showed the 
form characteristic for steel corrosion in neutral media with oxygen depolarization; all characteristic areas are visually traceable: active dissolution, initiation of passivation, passivation, complete passivity, passive state and trans passivity. The potential for complete passivation is about 0 $\mathrm{mV}$, the potential for trans-passivity is about $1200 \mathrm{mV}$, the current density at the point when passivation has started is $0.91 \mathrm{~A} / \mathrm{m}^{2}$, the current density in the passive state is $0.23 \mathrm{~A} / \mathrm{m}^{2}$. When $0.5 \mathrm{~g} / \mathrm{L}$ of xanthane hydride was added, a decrease in the current density to $0.36 \mathrm{~A} / \mathrm{m}^{2}$ at the point of passivation start was observed, the current density in the passive state was decreased to 0.09 $\mathrm{A} / \mathrm{m}^{2}$. The potential of complete passivation does not change noticeably, but the potential of trans-passivity increases to $1340 \mathrm{mV}$. The addition of $1 \mathrm{~g} / \mathrm{L}$ of xanthane hydride leads to a further decrease in the current density to 0.12 $\mathrm{A} / \mathrm{m}^{2}$ (at the point when passivation has started), the current density in the passive state decreased to $0.02 \mathrm{~A} / \mathrm{m}^{2}$. The potential for complete passivation is slightly reduced (to $-20 \ldots-50 \mathrm{mV}$ ), and the trans-passivity potential rises to $1450 \mathrm{mV}$. It can be concluded that xanthane hydride is a fairly effective inhibitor of corrosion of carbonized steels in neutral aqueous media with oxygen depolarization. The coefficient of corrosion inhibition, estimated from the reduction in the anode current density in the passive state, has a value of 11.5 .

The study of the effects of $\mathbf{1}$ as 2,4-D antidote was carried out on sunflower seedlings in the Laboratory of plant growth regulators of All-Russian Research Institute of Biological Plant Protection. The estimation of 2,4-D antidote activity was carried out by the original method developed in Laboratory of plant growth regulators, according to the reported procedure [4]. Briefly, sunflower seeds with an embryonic root length of 2-4 mm were placed for $1 \mathrm{~h}$ in a solution of 2,4-dichlorophenoxyacetic acid (2,4-D herbicide) in a concentration of $10^{-3} \%$ to get approx. $40-60 \%$ inhibition of hypocotyl growth. After the herbicidal effect has reached, the seedlings were washed with water 
and placed in solutions of xanthane hydride in concentrations of $10^{-2}, 10^{-3}, 10^{-}$ 4, 10-5\% (variant "herbicide + antidote"). The seeds of the "herbicide" variant (reference standard) were held for $1 \mathrm{~h}$ in a solution of 2,4-D at a concentration of $10^{-3 \%}$ and then $1 \mathrm{~h}$ in pure water. The protective (antidote) effect was estimated by increasing the length of a hypocotyl and the root in the variant "herbicide + antidote" with respect to the length of a hypocotyl and the root in the variant "herbicide" (reference standard). Statistical calculations of experimental data were performed using Student's t-test at $\mathrm{P}=0.95$. As it was found, xanthane hydride showed no significant 2,4-D antidote activity. Also we have studied the growth-regulating activity of xanthane hydride on sunflower seedlings. The effect was determined by increasing the length of the stem and root upon treatment with solutions of xanthane hydride in concentrations of $10^{-2}, 10^{-3}, 10^{-4}, 10^{-5} \%$. We found that xanthane hydride showed only weak plant growth regulating activity.

\section{References}

1. A. Z. Rys, D. N. Harpp. Xanthane Hydride / e-EROS Encyclopedia of Reagents for Organic Synthesis. 2008. URL:

http://onlinelibrary.wiley.com/doi/10.1002/047084289X.rn00881/abstract

2. C. Glidewell, J. S. McKechnie, P. J. Pogorzelec // J. Chem. Education, 1984, 61 (No 1), pp. 78-79.

3. N. V. Zhorkin, V. A. Ignatov, G. A. Blokh // Voprosy Khim. Khim. Tekhnol. 1972, № 2. - P. 176-186 (A review on the chemistry of xanthane hydride, in Russian) // Chem. Abstr. 1973, 78, 124470h.

4. V.D. Strelkov, L.V. Dyadyuchenko, I.G. Dmitrieva. Synthesis of new herbicide antidotes for sunflower. Krasnodar, 2014, 96 pp. (in Russian) 